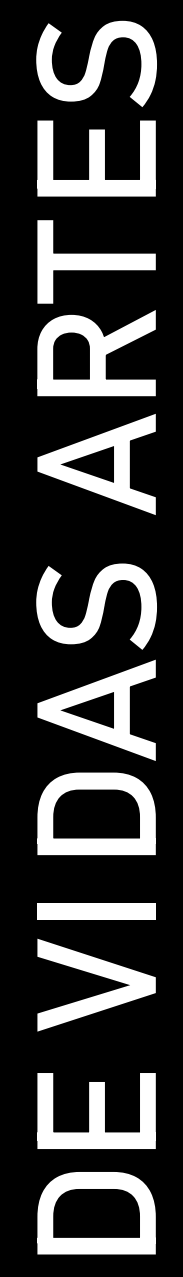

PAULA GUERRA E LÍGIA DABUL (EDS.) 


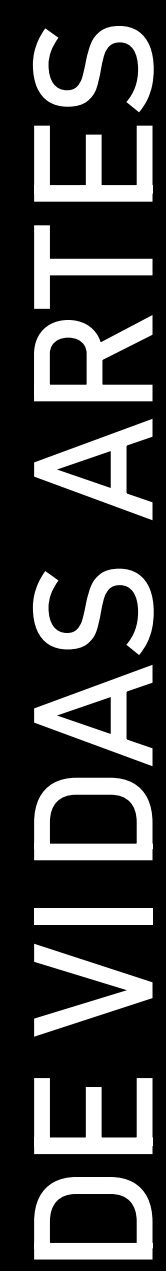

\section{PAULA GUERRA E LÍGIA DABUL (EDS.)}

Design por Irandina Afonso

Ilustração da Capa por Lua Celina

Publicado em Setembro 2019

Universidade do Porto. Faculdade de Letras

[University of Porto. Faculty of Arts and Humanities]

Porto, Portugal

ISBN 978-989-8969-18-7

Suporte: Eletrónico - Formato: PDF / PDF/A 


\title{
IV.4. A Arte Elétrica de Ser Português
}

\section{IV.4. The Electric Art of Being Portuguese}

\section{Tânia Moreira}

\section{Resumo}

Neste capítulo, abordaremos uma questão pouco estudada em Portugal: a música de dança eletrónica (MDE) e o psytrance. O que é estranho, dado o facto de que já possui uma longa história em Portugal. Mais, é um fenómeno social que nos permite estudar os fluxos culturais que ocorrem na globalização, bem como uma necessária renovação teórica no campo dos cultural studies, com o acionamento do reportório póssubcultural. Desta forma, após analisarmos resumidamente o surgimento da MDE, abordaremos o corpus teórico que enformou este estudo. Em seguida, para demonstrar a preponderância internacional deste fenómeno, apresentamos o retrato global da produção científica da eletrónica (MDE). Por fim, exporemos as principais características do psytrance português.

Palavras-chave: MDE, psytrance, teoria pós-subcultural, Portugal.

\begin{abstract}
In this chapter we will address a less studied phenomenon in Portugal: electronic dance music (EDM) and psytrance. This lack of study is quite strange, given the fact that it already has a long history in Portugal. Moreover, it is a social phenomenon that allows us to study the cultural flows that occur in the globalization process, as well as a necessary theoretical renovation in the field of cultural studies, with the activation of the post-subcultural repertoire. In this way, after a brief analysis of EDM's emergence, we will address the theoretical corpus that shaped this study. Then, to demonstrate the international preponderance of this phenomenon, we present the academic picture of the EDM in the world. Finally, we will address the main features of Portuguese psytrance.
\end{abstract}

Key words: EDM, psytrance, post-subcultural theory, Portugal.

\section{Princípio}

Apesar de pouco estudada em Portugal (Guerra, 2010b, 2013, 2016), a música de dança eletrónica (MDE) e, em específico, o psytrance, são elementos interessantíssimos para se analisar um conjunto de questões sociológicas. ${ }^{210}$ Vejamos: a globalização e a difusão de bens culturais, já que estamos a falar de um elemento cultural surgido nos chamados países do Sul e que se difundiu, e foi apropriado, pelos países do Norte, pondo de pernas

\footnotetext{
210 Este capítulo resulta do desenvolvimento por parte da autora da sua tese de doutoramento intitulada "A Paradise Called Portugal: Genealogia, retrato e prospetiva da (r)evolução da música eletrónica de dança (1980-2017) [A Paradise Called Portugal: Genealogy, portrait and prospect of the ( $r$ ) evolution of electronic dance music (1980-2017)]" no âmbito do 3. ${ }^{\circ}$ ciclo em Sociologia da Universidade do Porto e sob orientação científica da Professora Doutora Paula Guerra.
} 
para o ar as já vetustas teorias do imperialismo cultural; uma revisão teórica às teorias subculturais que dominaram os cultural studies durante décadas e com o seu ênfase sobrepolitizado não conseguia apreender as novas formas de pertença e compromisso adotadas pelos jovens. De igual modo, uma análise fina deste fenómeno permitirá limpar alguns preconceitos que surgiram e que ainda se mantêm sobre esta realidade, como a associação ao consumo de drogas, e, no plano científico, a um certa morte deste fenómeno.

Primeiro analisaremos a génese internacional da MDE e do psytrance; em seguida efetuaremos uma revisão teórica, acionado um conjunto de conceitos teóricos que achamos mais pertinentes para este estudo; em terceiro lugar, para provar a vitalidade do estudo da MDE mostraremos o retrato global da produção científica da Electronic Dance Music MDE, através de uma pesquisa e análise bibliográfica nas bases de dados Scopus e Sociology Source Ultimate (SSU). Por fim, exporemos de forma fina as principais características do psytrance português.

\section{Da música eletrónica experimental ao psytrance}

A emergência da MDE remonta à música produzida pelos Kraftwerk na Alemanha dos anos 1970. Esse surgimento não poderá ser dissociado de um processo mais vasto que, ao longo do século $\mathrm{XX}$, aliava cada vez mais a música ao aparato tecnológico. Assim, os grandes avanços tecnológicos que se fizeram sentir durante esse século possibilitaram o surgimento de novas formas de produção, divulgação e receção musicais. Reportando-nos ao caso específico da MDE, a banda alemã inovou devido à conjugação de uma matriz clássica europeia de produção musical com o uso de sintetizadores e computadores. Depois do surgimento dos Kraftwerk e das suas novas sonoridades, a popular music mudou indelevelmente (Guerra, 2010a: 41; 2010b: 152).

Nos anos subsequentes, esta nova sonoridade deu origem a uma profusão de géneros e subgéneros musicais infindável, todos eles definindose e distinguindo-se dos demais pelo seu forte recurso às máquinas (músicamáquina ou The Man-Machine, como se autointitularam os Kraftwerk num dos seus álbuns) e à maior relevância dada aos processos de criação musicais do que às performances, em que as músicas estimulam o corpo e a mente para o movimento e não tão tanto para processos de interpretação das suas letras. Aqui, as batidas, as melodias imperam e os seus protagonistas deixam de ser 
a banda/ o artista, os quais muitas vezes procuram operar dentro do anonimato. Assim, o local - o espaço, o território - adquire, no contexto da electronic music uma importância reforçada, na medida em que se assume como contexto fundamental para uma experiência plena e completa desta sonoridade - uma experiência repleta de emoções e de libertação do corpo e da mente, não raras vezes associada ao consumo de drogas (Guerra, 2010a: 41-43).

Nos finais dos anos 1980, a MDE vê surgir em Goa (Índia), os primeiros indícios de um novo género musical - o psytrance (na altura apelidado de Goatrance) - e, mais que isso, de uma nova cultura a ele associado - a psyculture. O psytrance nunca poderá ser dissociado da sua psyculture; isto porque não se trata apenas de mais um género musical, mas todo um estado de fruição musical, associado a diferentes formas de alteração da consciência humana, como substâncias psicoativas, dança, arte, meditação, oração, sexo ou yoga (Guerra, 2015: 309). Ou, como constata Sanches (2017), se antes a experiência começava e terminava com a música, agora passou a ser um modo de vida com repercussões políticas e até jurídicas. Desde a década 1990, o psytrance alastra-se pelo mundo inteiro, sendo hoje um dos movimentos juvenis com maior expressão na sociedade contemporânea e uma importante indústria que contribui não só para o setor musical, como também para o setor do turismo, do lazer ou da moda.

Em Portugal, o psytrance emerge como reação à decadência das raves de house e techno, em meados dos anos 1990. As primeiras festas psytrance eram ilegais, escondidas e seletivas; realizavam-se para um número muito reduzido de pessoas, geralmente provenientes das classes médias urbanas e bastante escolarizadas; e constituíam alternativas lúdicas e sociabilitárias assentes na defesa do new age e de um ethos (e estética) neo-hippie, do naturalismo, do vegetarianismo, do espiritualismo, do uso de drogas ao serviço da consciência e de uma busca de diferença (Guerra, 2015: 310).

Após o ano de 1997, aumenta a oferta de festas (surgem diversos DJs e produtores) e a sua procura (público). Para tal, foi fundamental o aparecimento do Boom Festiva ${ }^{11}$, considerado nos dias de hoje, um dos maiores festivais mundiais de psytrance e cultura alternativa. Organizado pela Good Mood Productions, em Idanha-a-Nova (Castelo Branco), o Boom 
Festival, em 2014, contou a presença de cerca de 30 mil participantes provenientes de mais de 150 países, estando ligado a uma alargada indústria de produção musical performativa, desde editoras independentes, organização e gestão de eventos, comunidades visuais, comunidades de sons e de redes sazonais de festas locais e festivais regionais (Guerra, 2015: 311). E quais os principais motivos para a frequência em festivais como o Boom Festival? Acima de tudo, dois: primeiro, a possibilidade de participar numa estética tribal; e, segundo, a vontade por demonstrar a diferença. $O$ Festival é, assim, um espaço (temporário) livre da regulação e repressão dos contextos institucionais habituais (Guerra, 2015: 313).

\section{A inevitabilidade de uma renovação teórica}

Situando-se nas correntes mais recentes da análise dos fenómenos musicais (ver Figura VI.4.1), Guerra (2015) postula que o psytrance deve ser explicado no quadro dos post-subcultural studies (tribos/neo-tribos/cenas), na medida em que este congrega atores de diferentes faixas etárias, meios socioeconómicos e gostos musicais, estando mais associado a novas formas de sociabilidade pós-modernas, caracterizadas por laços de afetividades temporárias e partilhas lúdicas. Tratam-se, portanto, das neo-tribos (Guerra, 2015: 314, 327). Declina-se, deste modo, uma leitura do psytrance feita exclusivamente à luz da teoria subcultural desenvolvida pelos cultural studies, por considerar que esta perspetiva tem tendências "totalizantes, normalizadoras e dicotomizadoras" (Guerra \& Quintela, 2016: 199): totalizante, porque concebe as subculturas como se de uma entidade única com características iguais e específicas se tratassem, negligenciando o facto de a juventude ser altamente diversificada que não cabe, inclusivamente, dentro dos limites etários administrativos e governamentais; normalizadoras, porque tendem a pensar os jovens e os seus grupos sob uma lógica que releva demasiado a classe e a idade e as apropriações criativas/ rebeldes das subculturas e descura o género, a raça, a etnia e as vivências menos rebeldes dos jovens comuns; e dicotomizadoras, porque tendem a fazer uso de oposições dicotómicas - cultura dominante vs. subordinada, autêntico vs. comercial, etc. - que influenciam as suas investigações e acabam por esconder a complexidade das subculturas (Guerra, 2010b: 407; Guerra \& Quintela, 2016: 199). 


\section{Tribos, neo-tribos}

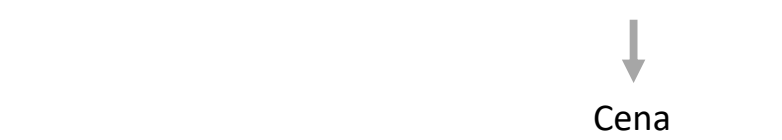

Art World

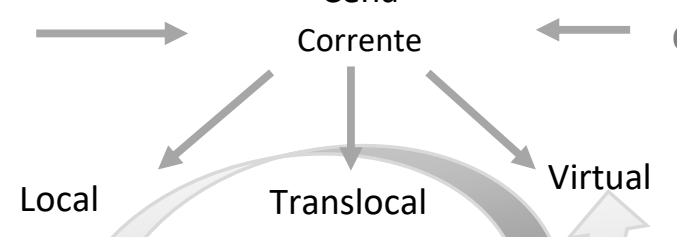

Campo Social

Etc.

Figura IV.4.1. Modelo teórico-analítico defendido por Guerra (2012 e 2015)

Fonte: Elaboração da autora

Neste contexto, existe uma opção pelas correntes teóricas que têm vindo a ser largamente desenvolvidas, sobretudo desde os finais da década de 1990. De forma resumida, podemos dizer que estas procuram empreender investigações baseadas num mix de teorias e conceitos suficientemente capaz de dar conta da realidade complexa e plural do campo cultural, dos seus atores, entidades, processos e obras; um mix, porque não existe uma teoria que consiga abranger toda a complexidade dos fenómenos aqui em causa.

Vejamos o primeiro conceito: o de tribo (ou neo-tribo), desenvolvido primeiramente por Maffesoli (2006) e mais tarde retrabalhado por Bennett (1999), pensa os grupos juvenis enquanto comunidades emocionais que emergem num contexto de grande velocidade e transitoriedade e que resultam de um desejo de pertença efémero, mutável e destruturado. A noção de art world, por outro lado, desenvolvida inicialmente por Howard S. Becker (2010) e apropriada por Diana Crane (1987) mais tarde, foca-se na compreensão dos processos de criação artística, concluindo que estes devem ser entendidos como apanágio coletivo fortemente dependentes da existência de uma cooperação e do estabelecimento de convenções/ normas/ regras. Já o conceito de campo, proposto por Pierre Bourdieu (2010), elabora o espaço social enquanto campo de lutas simbólicas onde coexistem múltiplas estruturas que ajudam a moldar o habitus e capital (social, cultural, etc.) dos agentes que, por sua vez, também influenciam essas mesmas estruturas no sentido de as transformar ou conservar. Finalmente, o conceito de cena espaço de possíveis concretizáveis - , alicerçando-se nos contributos teórico- 
empíricos dos conceitos anteriores e situando-se numa corrente pósestruturalista, é introduzido por Straw (1991: 6), o qual define a cena como

Um espaço cultural em que um conjunto de práticas musicais coexistem, interagem umas com as outras dentro de uma variedade de processos de diferenciação e de acordo com diferenciadas trajetórias de mudança e fecundação cruzada.

Ao mesmo tempo, as cenas podem assumir múltiplas configurações teatrais, literárias, musicais, etc. -, todas elas influenciando-se reciprocamente. Peterson e Bennett (2004), acompanhando o contexto de maior interconectividade entre atores e espaços proporcionado, entre outros fatores, pela crescente democraticidade da Internet, propuseram uma leitura tripartida das cenas, defendendo que estas podem ser locais, translocais e virtuais: locais porque apesar de toda a interconectividade, não deixa de existir um foco geográfico específico; translocal refere-se, acima de tudo, às distintas formas de música e de estilos de vida que emergem devido aos contextos de comunicação que não estão unicamente ancorados ao local; por fim, a cena virtual remete para a explosão do espaço físico, em que uma cena é criada e mantida no espaço virtual (Peterson \& Bennett, 2004; Guerra \& Quintela, 2016: 202).

\section{A música de dança eletrónica como objeto de investigação}

No sentido de se fazer um retrato global da produção científica da música de dança eletrónica (MDE), efetuamos uma pesquisa e análise bibliográfica nas bases de dados Scopus e Sociology Source Ultimate (SSU). A pesquisa foi realizada em março de 2018 , tendo como base a palavra-chave "electronic dance music" e resultou num total de 705 registos encontrados (174 registos no caso da base de dados SSU e 531 registos na base Scopus). Dos resultados apurados, é possível atestar uma clara tendência para um aumento do interesse por parte da academia no que diz respeito à MDE: entre 2002 (ano em que se regista o primeiro aumento significativo do número de publicações encontradas) e 2017, o número de publicações aumentou em média $25 \%$ por ano, sendo de relevar o peso dos artigos científicos no cômputo destes dados (Figura IV.4.2). 


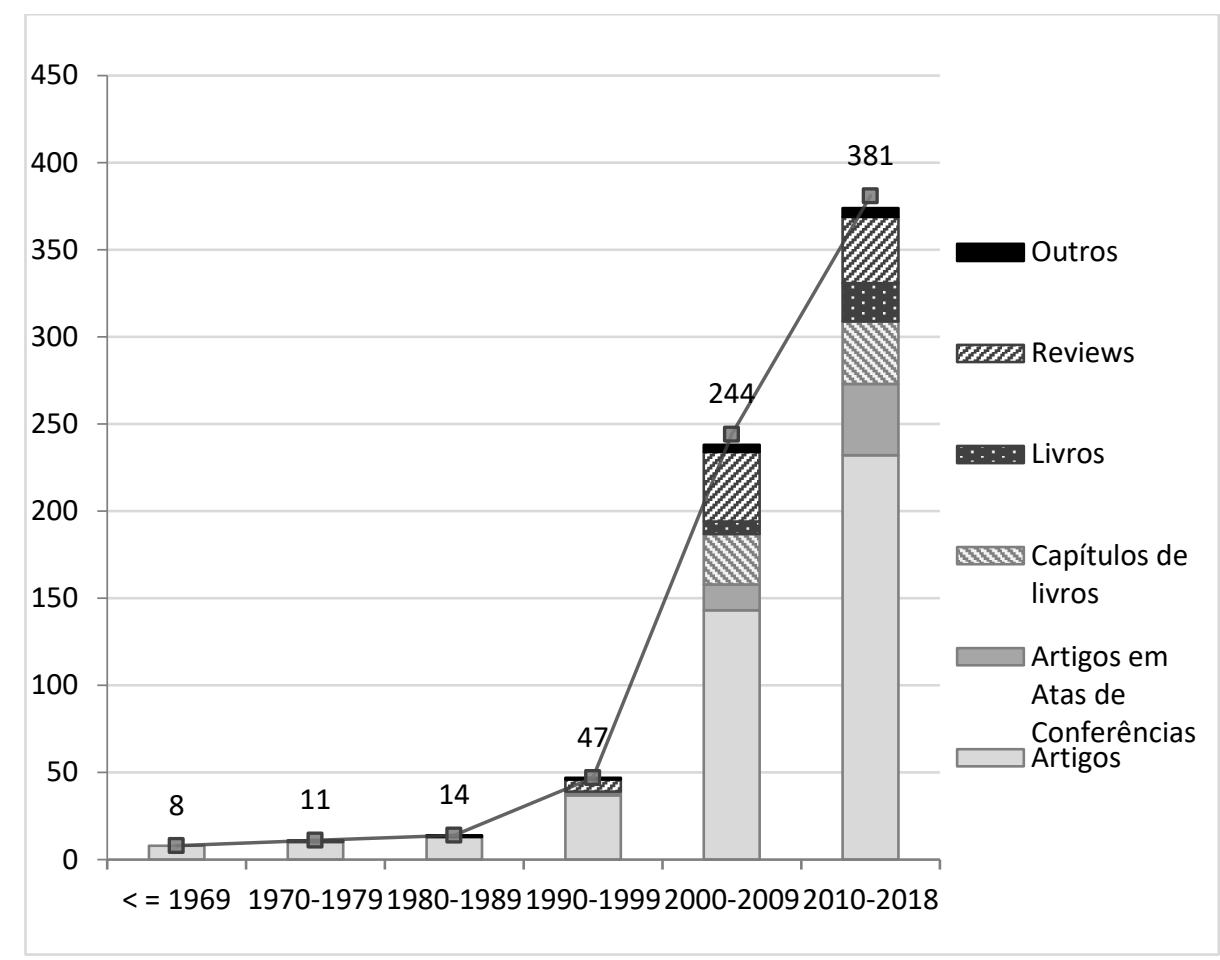

Figura IV.4.2: Número de publicações científicas sobre electronic dance music nas bases de dados Scopus e Sociology Source Ultimate, por década e tipo de publicação (número)

Fonte: Elaboração da autora.

Nota: Não foi possível encontrar a data e/ou tipo de publicação para 13 publicações.

Os artigos científicos parecem tender a assumir-se, de facto, como a principal fonte de divulgação da informação científica produzida em torno da MDE. Se atentarmos à Figura 3, constatamos que são os artigos aqueles que mais frequentemente são citados por outras publicações (veja-se a elevada diversidade de artigos que possuem entre 1 e 10 citações, na Figura IV.4.3) e que auferem o maior número de citações individualmente (através da Figura 3 , comprovamos que os mais elevados valores de citações surgem quase exclusivamente fruto dos artigos), querendo indicar uma especial importância deste tipo de publicação face às demais, neste segmento de estudo.

Em termos de distribuição geográfica, a produção da MDE tende a acompanhar os níveis de desenvolvimento socioeconómico dos vários países do mundo, sendo possível observar, através da Figura 4, uma particular incidência da produção científica nos países da América do Norte, da Europa, Oceânia e nos designados BRICS (Brasil, Rússia, Índia, China e África do Sul), ficando, assim, de fora muitos dos países da América Central e do Sul, bem como da África e Ásia. Os dados revelam-nos, sem surpresa, o peso dos Estados Unidos da América (EUA) e do Reino Unido (RU) no número de trabalhos publicados (respetivamente, 133 e 102 publicações), os quais se 
distanciam consideravelmente dos países que surgem em terceiro (Austrália, com 33 publicações) e quarto lugar (Alemanha, com 24 publicações), e mais ainda dos demais países cujo número de publicações se situa abaixo dos 20 trabalhos. Será, não obstante, de sublinhar o número de publicações portuguesas (7 publicações), na medida em que posicionam Portugal a par de países como a Itália, Coreia do Sul ou Áustria, e acima de países como a Suécia, Bélgica, Finlândia ou França.

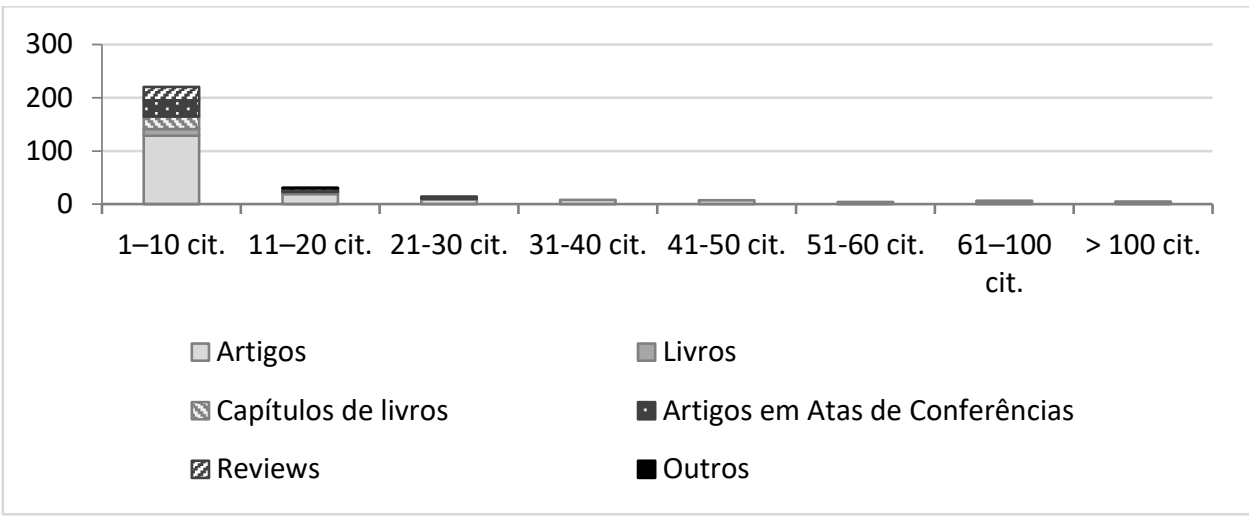

Figura IV.4.3. Número de publicações científicas sobre electronic dance music nas bases de dados Scopus e Sociology Source Ultimate, por número de citações e tipo de publicação (número)

Fonte: Elaboração da autora. Nota: O n.ำ de citações refere-se ao n.ำ de vezes que cada publicação aqui em análise é citada por outras publicações. Não foi possível encontrar o número de citações e/ou o tipo de publicação para 413 publicações.

Retornando, agora, a nossa atenção para o principal foco deste exercício analítico - artigos publicados nos últimos anos em revistas científicas internacionais -, constatamos que, entre 2000 e 2018, foram registados 375 artigos nas bases de dados em análise e que os EUA e o RU continuam a liderar o ranking, com 0 maior número de artigos publicados respetivamente, 70 e 61 publicações. Merece, aqui, dar particular ênfase ao crescente interesse académico pela MDE considerando o número de países onde as diferentes investigações se realizam: enquanto na década de 2000 se apresentam artigos provenientes de 21 países, na década de 2010, o seu número ascendeu aos 39 países - revelando um carácter policêntrico e territorialmente pulverizado.

Em termos de temáticas e de nós de ancoragem concetual, é possível verificar (Tabela IV.4.2), a partir de 2000, um interesse especial com os consumos e excessos (i)lícitos (substâncias psicoativas, álcool, tabaco), seguido pelas questões de género e sexualidade. Também a experiência sensorial através da dança ou os sentidos de pertença grupal se prefiguram 
como temáticas de relevo. As culturas juvenis parecem suscitar um importante interesse, tendo sido acompanhadas, em anos mais recentes, com o seu oposto - ageing subcultural. A abordagem etnográfica assume-se como a principal perspetiva metodológica das investigações realizadas certamente devido ao facto de possibilitar uma descrição densa dos contextos, cenas e circuitos da EDM. A Figura IV.4.5. apresenta um Mind Map elaborado a partir das palavras-chave predominantes nos artigos analisados.

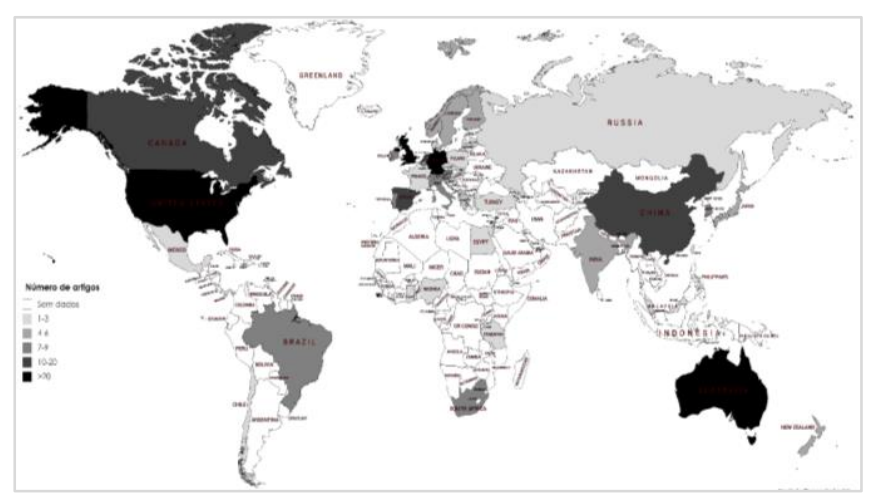

Figura IV.4.4. Número de publicações científicas sobre electronic dance music nas bases de dados Scopus e Sociology Source Ultimate, por país (número)

Fonte: Elaboração da autora.

Nota: Não foi possível identificar o país em 224 publicações.

Tabela IV.4.2: Número de artigos científicos sobre electronic dance music nas bases de dados Scopus e Sociology Source Ultimate, por palavras-chave identificadas (número)

\begin{tabular}{|l|c|l|c|}
\hline Palavras-chave & N.-artigos & Palavras-chave & N.o artigos \\
\hline Drugs & 233 & Club culture & 25 \\
\hline Music & 173 & DJ & 21 \\
\hline Gender and sexuality & 132 & Subcultures & 19 \\
\hline Electronic dance music & 97 & Youth culture & 18 \\
\hline Dance, dancing & 76 & Identities & 18 \\
\hline Adolescents, youth & 68 & Nightclubs & 16 \\
\hline Dance music & 67 & Arts & 11 \\
\hline Culture & 58 & Ethnology & 10 \\
\hline Adults & 52 & Ethnography & 10 \\
\hline Human & 45 & Community & \\
\hline Rave culture & 30 & Authenticity & \\
\hline Popular music/culture & & & \\
\hline
\end{tabular}

.Fonte: Elaboração das autoras Nota: Por motivos de simplificação, apresentamos apenas as palavraschave identificadas em 10 ou mais artigos científicos. 


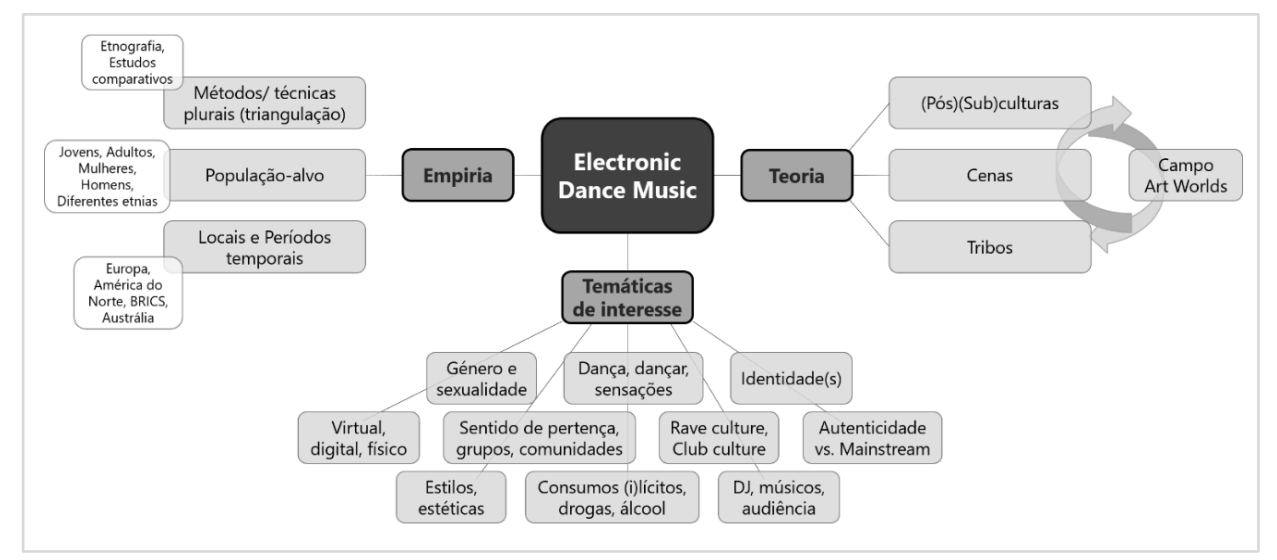

Figura V.4.5: Mind Map em torno da Electronic Dance Music

Fonte: Elaboração da autora. Nota: Mind Map construído a partir de palavras-chave predominantes dos artigos analisados entre 2000 e 2018.

\section{Da teoria à prática: o vivido do psytrance português}

Por fim, e com base no edifício teórico descrito anteriormente, estabelecemos a nossa pesquisa sobre o psytrance português, uma pesquisa consubstanciada metodologicamente na análise de 20 entrevistas a DJs, produtores e músicos de música eletrónica e na recolha e tratamento sistemáticos de informação junto do site Psypartys - eventos realizados durante Janeiro 2010 e Novembro 2014 (Guerra, 2015).

Dessa análise, e antes de passar ao escrutínio do psytrance sob o ponto de vista das cenas propriamente ditas, concluímos que o psytrance/ psyculture em Portugal caracteriza-se pelas seguintes características-chave:

- uma forte fluidez/mutabilidade/efemeridade, não só ao nível da sua fruição, como também ao nível da produção, onde criadores, intermediários e público facilmente assumem diferentes identidades/gostos musicais;

- identidades plurais: não é possível identificar uma identidade comum nos públicos das festas, a não ser a junção decorrente da partilha e pertença aos espaços da festa e quiçá a sua organização;

- laços de afetividade temporários: a interação é passageira e temporariamente situada, desaparecendo assim que os indivíduos saem da pista de dança;

- uma visão sobre o ciberespaço como uma nova praxis - socialidades cibernéticas -, o qual é, muitas vezes, utilizado como ferramenta de fomento e potenciação de movimentos de protesto e reivindicação 
heterogéneos: desde sustentabilidade ecológica até anticapitalista. Mais do que quererem atacar a organização estatal, os psytrancers procuram fragilizar os códigos culturais dominantes, organizando-se, para isso, em torno de movimentos informais que associam variados grupos ativistas desglobalizados;

- uma defesa da ética do-it-yourself (DIY) - muito ligada àquelas sociabilidades cibernéticas - com impactos ao nível da produção de música, da preparação de festas ou da organização de movimentos de contestação;

- e pela apologia de uma ação direta capaz de oferecer soluções efetivas/reais, através da formulação de propostas sociais e políticas mais ou menos concretas.

Como elementos distintivos da cena psytrance em Portugal, podemos destacar a dimensão espacial, já que no início as raves constituíam festas ilegais que se realizavam em sítios remotos e em grandes espaços; com o passar do tempo, e em paralelo com as festas de maior dimensão, surgem eventos com uma escala mais reduzida nas cidades. Apesar de tudo, existe uma preferência pelos eventos que ocorrem em espaços abertos, assente na procura da liberdade e na busca de uma relação de autenticidade do homem com a natureza.

Este dado conduz-nos ao segundo elemento caracterizador desta cena: a rutura com o quotidiano. A rave é experienciada como um momento de alienação/libertação face aos problemas do quotidiano, com as suas preocupações e responsabilidades. No fundo, um espaço de hiper-realidade em que se procura sensações e prazer (Guerra, 2015: 320). Mas se é verdade que existe esta busca pela libertação/alienação, não é menos verdade que continua a existir também um desejo de integração social e material que faz com que os frequentadores das raves concedam igual importância às esferas profissionais e escolares. Estamos, pois, perante um dos paradoxos pósmodernos.

O terceiro elemento distintivo da cena psytrance portuguesa diz respeito à sua geografia, a qual evidencia uma elevada dispersão das festas psytrance pelo território português, muito embora se trate de um fenómeno que acaba por acompanhar a distribuição dos eventos e festivais de música em geral e de pop rock em Portugal, com forte concentração de eventos nas duas 
maiores cidades do país - Lisboa (14,78\%) e Porto $(10,26 \%)$ - e, por consequência, nas duas áreas metropolitanas portuguesas - Grande Lisboa $(15,83 \%)$ e Grande Porto (13,74\%) —, revelando que também aqui têm impactos as diferentes dinâmicas de desenvolvimento económico, social e cultural dos diversos municípios (Figura 6). Não obstante, esta geografia é explicada por uma forte intensidade de cenas locais de psytrance, que nos leva a não descurar o seu cruzamento com cenas translocais, sendo que essas cenas translocais no caso português assumem a forma, muitas vezes, de festivais. O Boom Festival é um claro exemplo de uma cena que para além de local, é também translocal e inclusivamente virtual, pois contribui para o delineamento de uma comunidade que vai para além das fronteiras nacionais e que se comunica virtualmente (Guerra, 2015).

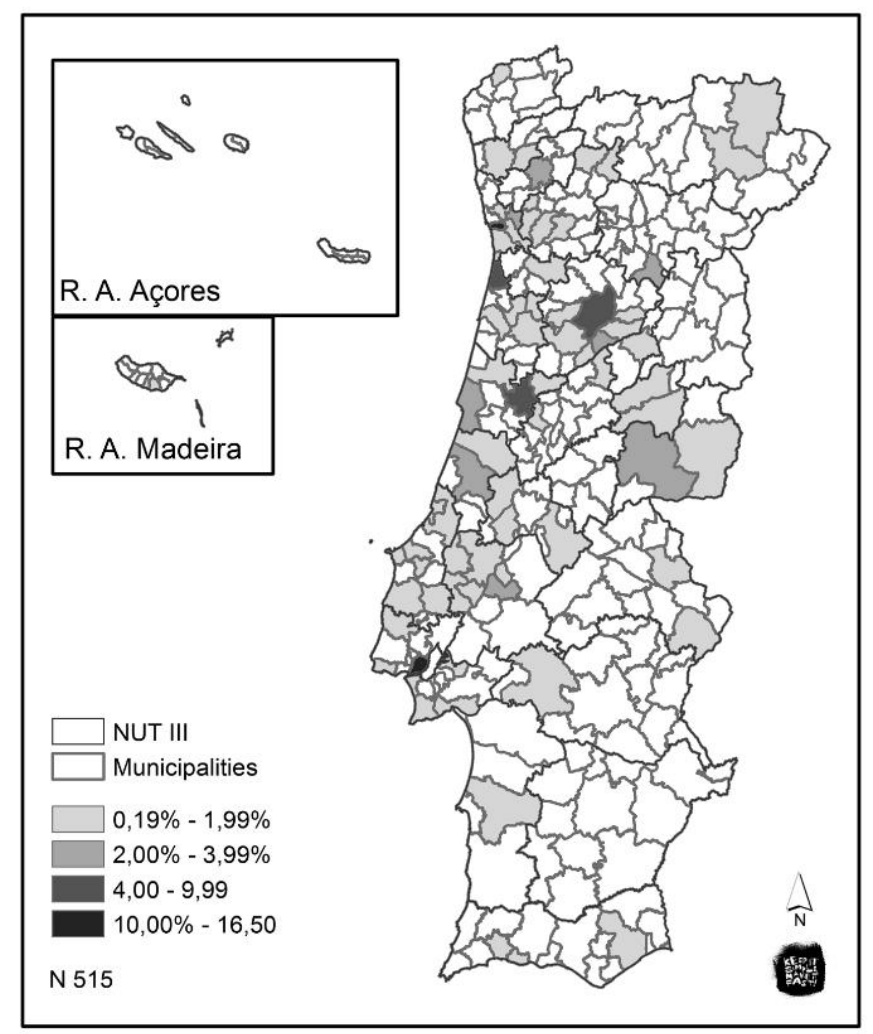

Figura V.4.6: Distribuição de eventos psytrance pelos municípios portugueses, entre janeiro de 2013 e novembro de 2014

Fonte: Guerra (2015: 323).

O quarto e último elemento distintivo das raves psytrance tem que ver com a sua autenticidade. Aqui, apoiando-nos em Anderson e Kavanaugh (2007), é possível distinguir três componentes desta autenticidade: a primeira componente diz respeito ao ethos PLUR (Peace, Love, Unity, Respect) assente numa sociabilidade empática entre pessoas muito diferentes que partilham uma mesma busca de sensações e uma dada relação com a 
música, com o espaço, com os outros. No entanto, estas raves não deixam de ser espaços de reprodução das desigualdades sociais, já que o seu acesso não deixa de ser economicamente condicionado. Não é, por isso, de estranhar que sejam espaços frequentados, grosso modo, pelas classes médias urbanas fortemente escolarizadas. Mais do que isso, a frequência nestes espaços está também associada a uma reivindicação de gosto e de distinção, o que é percetível na repulsa à crescente abertura e massificação das festas. Uma posição, diga-se, pouco em linha com o ethos PLUR (Guerra, 2015: 322). A segunda componente da autenticidade relaciona-se com as formas de organização das raves psytrance, as quais são, geralmente, divididas em diferentes salas ou tendas com géneros musicais distintos - 0 que se associa ao ethos PLUR - e organizadas de uma maneira informal, recorrendo à ética do-it-yourself e ao uso da Internet para fazer a sua divulgação. (Guerra, 2015: 323)

Finalmente, a terceira componente da autenticidade das raves refere-se às normas e comportamentos nelas praticados. Comportamentos, tais como, dançar até às primeiras horas da manhã, aos quais são acrescentados valores de independência e conexão, consumo de drogas ilegais, o que acaba por provocar nos participantes efeitos de comunhão e transcendência por um período alargado de tempo (Guerra, 2015: 325). Neste ponto, é de referir ainda que, em Portugal, os eventos psytrance exibem uma duração que varia entre um e sete dias, sendo que os eventos de dois dias são os predominantes $(93,91 \%)$, ocorrendo por norma aos fins-de-semana e de forma ininterrupta.

Considerando todos estes elementos caracterizadores da cena psytrance, é possível discordar de todos os autores (Anderson, 2009) que têm postulado a morte das raves, fruto da sua crescente comercialização e de uma suposta perda de autenticidade e influência na cultura popular. Ao invés, defendemos que assistimos, isso sim, a uma multiplicação de cenas, nós e canais na realidade portuguesa, bem como a metamorfose de cenas locais em cenas translocais e virtuais (Guerra, 2015).

\section{Pistas conclusivas}

Como já mencionado, depois dos Kraftwerk, a popular music nunca mais foi a mesma. A sua criatividade aliada aos novos instrumentos tecnológicos fez emergir, nos anos 1970, uma nova sonoridade que marcaria para sempre o 
campo musical - a electronic dance music. Nos anos 1980, esta nova sonoridade via surgir em Goa (Índia), os primeiros indícios daquilo a que se iria chamar de psytrance e de um lifestyle a ele associado - a psyculture. Durante os anos 1990, este psytrance e psyculture alastram-se pelo mundo inteiro, chegando a Portugal em meados da década de 1990, por via da organização de festas de pequena dimensão, ilegais, escondidas e muito seletivas - geralmente, direcionadas para pessoas provenientes das classes médias urbanas e bastante escolarizadas. Após o ano de 1997, com o surgimento do Boom Festival, o psytrance começa a consolidar-se cada vez mais em Portugal, aumentando a oferta festiva e o seu público.

A análise deste fenómeno deverá ser tributária dos post-subcultural studies, na medida em que se trata de um fenómeno complexo e diversificado que as teorias subculturais - teorias com tendências totalizantes, normalizadoras e dicotomizadoras - não conseguem explicar devidamente. Assim, o psytrance será melhor entendido se analisado num mix de teorias que congregue conceitos como o de tribo, art world, campo ou cena. É com base nesse corpus teórico que apresentamos as principais características e traços distintivos da cena psytrance portuguesa, uma cena composta por processos fluídos/mutáveis/efémeros, identidades plurais, laços de afetividade temporários, defensora do ciberespaço, da ética do-it-yourself e da ação direta enquanto mecanismos eficazes e capazes de oferecer soluções reais e efetivas para alguns dos problemas vivenciados. É ainda uma cena onde persiste uma preferência pelas festas ao ar livre (dada a extrema importância concedida à relação homem-natureza) e onde existe uma busca pela alienação/libertação como forma de romper com o quotidiano. Uma cena que se encontra dispersa por todo o território nacional, mas que acaba por se assemelhar a tantos outros fenómenos sociais em Portugal, ao exibir uma maior concentração de eventos nas duas principais cidades do país - Lisboa e Porto. E, finalmente, uma cena que revela três componentes de autenticidade: uma primeira relacionada com o ethos PLUR (Peace, Love, Unity, Respect) assente numa sociabilidade empática entre pessoas muito diferentes; uma segunda relativa às formas de organização das festas psytrance baseada em lógicas multi-oferta, informais, do-it-yourself e virtuais; e uma terceira componente que diz respeito às normas e comportamentos vivenciados nas raves psytrance (dançar até de manhã, sob valores de independência e conexão e, por vezes, sob o efeito de drogas ilegais). Por 
fim, defendemos que mais do que postular a morte deste fenómeno (como de resto de outros fenómenos musicais e culturais), é necessário reconhecer-se a sua mutabilidade e adaptabilidade a novos contextos, a novos tempos, a novas gerações - estes fenómenos não morreram, eles transformaram-se.

\section{Referências Bibliográficas}

Anderson, T. L. (2009). Rave Culture: The alteration and decline of a Philadelphia music scene. Philadelphia, PA: Temple University Press.

Becker, H. S. (2010). Mundos da arte. Lisboa: Livros Horizonte.

Bennett, A. (1999). Subcultures or neo-tribes? Rethinking the relationship between youth, style and musical taste. Sociology, 33(3), pp. 599-617.

Bourdieu, P. (2010). A distinção. Uma crítica social da faculdade do juízo. Lisboa: Edições 70.

Crane, D. (1987). The transformation of the avant-garde: The New York art world, 19401985. Chicago: Chicago University Press.

Guerra, P. (2010a). Dance music, sons, reflexos e trânsitos: traços de uma cena no Norte de Portugal. In Lopes, J. T. (coord.), Boia, P. S., Ferro, L. \& Guerra, P. (Eds.). Género e música eletrónica de dança: experiências, percursos e «retratos» de mulheres clubbers (pp. 39-67). Lisboa: Comissão para a Cidadania e Igualdade de Género.

Guerra, P. (2010b). A instável leveza do rock: génese, dinâmica e consolidação do rock alternativo em Portugal. (Tese de Doutoramento). Porto: Faculdade de Letras da Universidade do Porto.

Guerra, P. (2013). A instável leveza do rock. Génese, dinâmica e consolidação do rock alternativo em Portugal (1980-2010). Porto: Afrontamento.

Guerra, P. (2014a). Punk, ação e contradição em Portugal. Uma aproximação às culturas juvenis contemporâneas. Revista Crítica de Ciências Sociais, 102-103, pp. 111-134.

Guerra, P. (2014b). Punk, expectations, breaches and metamorphoses: Portugal, 19772012. Critical Arts, 28(1), pp. 111-122.

Guerra, P. (2015). Flying away: electronic dance music, dance culture, psytrance, and new sounds in Portugal. In E. Simão, A. M. Silva, \& S. T. Magalhães (Eds.), Exploring psychedelic trance and electronic dance music in modern culture (pp. 307-336). Hershey: IGI Global.

Guerra, P. (2016). Keep it rocking: the social space of Portuguese alternative rock (1980-2010). Journal of Sociology, 52(4), pp. 615-630.

Guerra, P., \& Quintela, P. (2016). Culturas urbanas e sociabilidades juvenis contemporâneas: um (breve) roteiro teórico. Revista de Ciências Sociais, Fortaleza, 47(1), pp. 193-217. 
Maffesoli, M. (2006). O tempo das tribos: o declínio do individualismo nas sociedades de massa. Rio de Janeiro: Forense Universitária.

Peterson, R. A., \& Bennett, A. (2004). Introducing music scenes. In A. Bennett \& R. A. Peterson (Eds.), Music scenes: local, translocal and virtual (pp. 1-15). EUA: Vanderbilt University Press.

Sanches, I. (2017, 18 November). E Portugal levantou-se: a revolução da dança eletrónica nos anos 90. Observador. Disponível em http://observador.pt/especiais/eportugal-levantou-se-a-revolucao-da-danca-eletronica-nos-anos-90/

Silva, A. S., \& Guerra, P. (2015). As palavras do punk. Lisboa: Alêtheia.

Straw, W. (1991). Systems of articulation, logics of change: Communities and scenes in popular music. Cultural Studies, 5(3), pp. 368-388. 